\title{
“Do not Make to eat to Troll!": The Dark Side of Web
}

\author{
Concetta Papapicco \\ University of Bari, ITALY \\ (iD) 0000-0003-3240-8740 \\ concetta.papapicco@uniba.it
}

\section{Isabella Quatera}

University of Bari, ITALY

(iD) 0000-0002-2732-1176

\author{
ARTICLE INFO \\ Received: 19 March 2019 \\ Accepted: 3 May 2019 \\ Published: 8 May 2019 \\ DOI: https://doi.org/10.29333/ojemt/5764 \\ ABSTRACT
}

Post-modernity is characterized by virtual phenomena, such as trolling, which undermine the relationship of trust and the image of the Self. Just in anonymity, these special Internet users pursue their provocation goals. At the individual level the phenomenon of trolling involves the splitting between real identity and virtual identity with socially unacceptable behaviors. The research aims to analyze fake profiles and their interactions with quali-quantitative methodologies, through Emotional Analysis, from which it is possible to extract a dataset, useful for the promotion of a digital social culture, in which the Net is the place where it develops connective intelligence.

Keywords: social identity, troll, fake identities, hostile communication, social network

\section{THE "DARK" SIDE OF WEB AND THE NEW DIGITAL IDENTITIES}

Following the great Digital Revolution, the "fluid" man changes not only the perception of what he lives, but also the very essence of the experience, that is the "Who is", hence his identity: a re-written identity using the computer. Redefining your identity in a digital context is, in many ways, beneficial because it allows you to take time to rethink and choose descriptions, photos or videos best suited to the desire to be constantly visible. In particular, the strong wave of social networks has initially differentiated the virtual and digital identity constructs. Virtual identity is the set of potentials, expectations and imaginations that have not yet materialized in the online environment: on the contrary, digital identity is the result of the process of "rethinking in an online context". Subsequently, the aforementioned distinction was canceled with the predominance of the digital identity over the virtual one. It is a multiple digital identity because it can be confirmed or disconfirmed, real but also fake, where the subjects can choose different ways to express themselves and interact with other subjects. Indeed, it is above all thanks to the endless possibilities of freedom offered by the Net and to this constant man-machine relationship, which gives rise to a new fragmented "Who", incapable also of distinguishing reality from virtuality, driven by the uncontrollable fantasy of being able to become another from himself. Thus, in the age of post-modernity, the computer becomes a subjective medium, which, as stated by the American sociologist and psychologist Sherry Turkle (2005): 
"We explicitly address the computer for experiences that we hope will be able to change the way we see or influence our social and emotional lives. When you venture into roleplaying games or fantasy worlds, or when you reach a community to meet friends and virtual lovers, you no longer think of computers as an "analytical machine". We are discovering the computer as a machine for intimacy".

Undoubtedly, if on the one hand the Net multiplies the possibilities of creating digital identities, on the other, lacking distinctive indices to depict, such as the tone of the voice or particular facial expressions, traits, that is, that belong only to the person as dematerialized (a physical Chi), virtual spaces provide more freedom to avoid being identified. On the one hand, digital identity is in extreme need of anonymity because it allows open discussion of very intimate topics in relative security; on the other hand, however, the mere omission of the name could give rise to hostile behavior, it can be to encourage aggression because it makes behavior more uninhibited, less conditioned by conventions and social norms. Anonymity is characterized by the desire not to authenticate, to act in an invisible and sometimes provocative manner: this is one of a darkest side of web. When provocative action has a function of fun, we witness the phenomenon of 'trolling': it is about people who deliberately try to create discussions or sow discord with negative comments, insults or provocations, trying to lengthen the time for discussion. In fact, acting like a troll is a game of false identity, performed without the consent of the other participants. The troll tries to be accepted as a legitimate user and intervenes as long as the other participants do not recognize the false identity or until the fun that the troll tries to act provocatively decreases. When, however, the troll uses a hostile communication, as insults related to the character, professional competence or physical appearance of a person, the most natural reaction is to respond in the same way; or that of responding with a certain amount of aggression, proportional to the offense, as the quarrel intensifies, people use increasingly offensive expressions. All this is amplified in a virtual environment because even those who try to placate the discussion from the outside remains involved, while employing irony. At the individual level the phenomenon of trolling involves the splitting between real identity and virtual identity, acting with socially undesirable behavior. The studies on the topic were of an interdisciplinary nature and were born as a result of the Social Network Revolution and therefore following the evolution of opportunities that the Network has provided.

\section{TROLLING: A REVIEW OF INTERNATIONAL LITERATURE}

Online trolling is a practice of deceptive and destructive behavior in a social environment like the Internet, with no apparent instrumental purpose. The trolls share many features of the classic villain of Joker: a modern variant of the Trickster archetype of ancient folklore. Just like the Joker, trolls act as agents of chaos on the Net, taking advantage of "hot-button issues" (a problem or a collective concern that is usually controversial in public opinion, which triggers an immediate intense reaction) to bring up the users overly emotional or crazy in some way. If an unfortunate person falls into their trap, the trolling intensifies for further, ruthless fun. This is why novice Internet users are regularly warned with: "Do not feed the trolls!".

Existing literature is sparse and multidisciplinary in nature (Herring, JobSluder, \& Scheckler, 2002). For example, Shachaf and Hara (2010) have conducted interviews with the trolls of Wikipedia, finding topics such as boredom, attention research, revenge, pleasure, desire to cause damage to the community between their motivations expressed for trolling. In other research, Hardaker (2010) conducted an analysis of the content of 
Usenet posts that identified four main characteristics of trolling: aggression, deception, interruption and success.

According to the authors of two Canadian studies "Trolls just want to have fun" (Buckels, Trapnell, \& Paulhus, 2014) on the perception of trolling, the respondents $(\mathrm{N}=$ 1215) completed personality questionnaires and a survey of their styles of commentary on Internet. Overall, strong positive associations emerged between the frequency of online comments, trolling enjoyment and the identity of the trolls, highlighting a common construct at the base of the measures taken. Both studies revealed similar patterns of the relationship between trolling and dark tetrad of the personality: trolling is positively correlated with sadism, psychopathy and Machiavellism. The studies performed used both enjoyment evaluations and identity scores. Of all the personality measures, sadism showed the most robust associations. The pleasure of other online activities, such as chatting and discussing, were not related to sadism. So according to these studies cybertrolling seems to be a manifestation of the Internet of daily sadism.

Still in the context of the studies conducted by Buckels, Trapnell, and Paulhus (2014), the disruptive and "nonsensical" aspects can distinguish trolling from other forms of online antisociality such as cyberbullying, where identities are usually clear (Lenhardt, 2013) and the intent is more direct. The frequency of the activity is an important correlation of the antisocial uses of the technology. For example, cyber bullying is often perpetrated by heavy Internet users (Juvonen \& Gross, 2008), and unpleasant people use mobile technologies more than others, not for socializing, but for personal entertainment. Still other research has linked the low pleasantness, the low conscientiousness and the high extroversion to the heavy use of the Net (Andreassen, Griffiths and Gjertsen, 2013). These models parallel gender differences in online behavior: men according to Joiner, Gavin, and Duffield (2005) use much more the Internet and have higher levels of antisocial behavior online. Overall, the results suggest that it might be useful to examine the trolling associations with the Big Five, gender differences and global Internet habits. The variables of harmful personalities known as Dark Tetrad of the personality: narcissism, Machiavellism, psychopathy and sadistic personality (Buckels, Jones, \& Paulhus, 2013). Their relevance is suggested by the research linking these traits to bullying to adolescents and adults.

Useful research shows that the narcissists (Ljepava, Orr, Locke, \& Ross, 2013) and those with antisocial personality disorder (Rosen, Balena, Rab, Carrier and Cheever, 2013) use Facebook more frequently than others, thus indicating that dark part of personality and to show where the trolling comes from. After all, trolling culture embraces a concept practically synonymous with sadistic pleasure in troll-speak (Buckels et al., 2013).

In conclusion, through these studies on trolling, antisocial individuals are more likely to connect with others like them and to pursue their personal brand of "self-expression" more than they did before the advent of the Social. The troll character seems to be a malevolent case of a virtual avatar (Dunn \& Guadagno, 2012; McCreery, Krach, Schrader, \& Boone, 2012), which reflects the real personality and his own ideal self.

Together with these studies, Coles and Wes (2016) confirm that 'trolling' can have multiple, inconsistent and incompatible meanings, depending on the context in which the term is used and according to the purposes of the person using the term. Coles and Wes (2016), tracing the data of 14 online forums with the relevant newspaper comment threads, have identified in the online messages: easily identifiable trolls; nostalgic trolls; 
trol that communicate vigilantism and trolls purely malicious. Therefore, neither the "troll" category nor the "trolling" action have a single fixed meaning. Each online tolling action can be presented as desirable or undesirable, depending on the purpose at the time of publication on the Internet. These actions also occur during online computer game sessions (Thacker \& Grifths, 2012), online encyclopedias (Shachaf \& Hara, 2010), online newspapers (Ruiz et al., 2011) and online petitions (Virkar, 2014).

In online newspapers reserch, comments in online news it could be the contemporary arguments as in the eighteenth-century cafés that founded the public sphere. This article assesses to what extent these forms of digital discussion adapt to the Habermas principles for democratic debate, using its discursive ethics as a demanding normative reference point. The sample of over 15,000 comments was selected from the online versions of five national newspapers of different political and journalistic contexts: The Guardian (United Kingdom), Le Monde (France), The New York Times (United States), El País (Spain) and La Repubblica (Italy). The ethical guidelines and legal structures established by the newspapers and their moderation strategies have been considered to understand the different settings of the conversations. Two models of public participation emerge from the analysis, one in which debate communities are formed based on mostly respectful discussions between different points of view and another of homogeneous communities, in which expressing feelings about current events dominates the contributions and it is less than a discussion topic

As part of online games, trolls tend to play longer game sessions. Frequent trolls are significantly younger and male. The type of trolling includes: griefing, sexism / racism and false / intentional failures and the motivation of trolling, in online gaming environments, include: fun, boredom and revenge (Thacker \& Grifths, 2012).

According to Ditrich and Sassenberg (2017), moreover, within the Facebook groups, where not all the members must necessarily adhere to the rules of the group itself, according to explicit or implicit rules, they show a deviant behavior. According to a model based on the social identity approach regarding responses to the deviations of rules in Facebook groups, deviant members were perceived as a questioning of what the group represents, subverting the identity of the group itself. Subsequently to these perceptions of identity subversion, the members of the group, in turn, were motivated to control and exclude the "deviated". It has been noted that together with these behaviors, participants usually ignore the contributions of those who have decided to exclude them, not recalling them after having read the timeline of the online group. This, however, does not seem to lead to the decadence of a social group, but promotes a "natural purification" within the group itself, through the elimination of negative influences. The trolls within the Facebook groups have been categorized as: grumpy, fanatical, sadistic liars, illiterate and irrational bigots.

\section{TROLLS ALERT: A GAME OF FALSE IDENTITIES}

In post-modernity and with the birth of the "Net-lingo", we are witnessing the diffusion of the terms "troll" and "fake". In constructing a false identity, an Internet user fake weaves the dense web of relationships and communications about deception; but when the goal of a fake profile is to provoke or hit someone by enjoying pleasure and fun, one is faced with the construction of a character who lives in fiction but with the goal of harming. Starting from this current assumption, the research aims to analyze fake profiles on the most famous hunting ground, such as social networks, from which a taxonomy will be created and the related study of interactions with qualitative-quantitative methodologies, 
using Emotional Analysis; which will provide the polarity of the 'diatexts' (Manuti \& Mininni, 2017), through which it will be demonstrable how real users react in case of trolling and in hostile communication contexts. Therefore, the four fake "unmasked" profiles were analyzed through the semiotics of the images of the aforementioned profiles. Furthermore, the interactions of the identified profiles were collected, which were analyzed with quanti-qualitative methods. Emotional Anlysis allows us to understand how the interactions of two groups of users (trolls and real users) are emotionally colored and what strategies real users put in place to react to provocations. The diatextual analysis of the "troll" interactions, as qualitative methodology, has allowed to detect the signification practices deriving from the dense plot of intertwining of text and context of enunciation, providing the possibility to draw up a taxonomy of profiles and trolling functions, with the expectation that it can be a valid support to the creation of algorithms able to favor the identification of a dataset useful for the promotion of a digital culture.

\section{The Semiotics of Troll Images}

Sight is one of the most attractive senses of the human being, as it communicates messages immediately with respect to the written text. An image is the privileged and mediated way to pass quickly from the level of the signifier (plane of the expression) to that of the meaning (plan of the content). Being continually immersed in a semi-sphere, even the art of creating false virtual identities is becoming a game of attractiveness that makes many users fall into the trap because, starting from the images, the rapid transition from the signifier to the meaning is difficult. In general, the creation of a virtual profile, for example on a social network like Facebook, becomes a way of representing oneself that captures certain particular aspects of one's personality to be identified. Since the function of a troll is not to be recognized, generating a profile becomes a real creative act, which can however provide important information at a sign level, for example, on the photo of the loaded profile or on the name choice. For this reason, a semiotic analysis of the profile images of four trolls recognized as such by users was conducted. The semiotic analysis of images is a methodology that allows to trace meanings within visual objects and is based on the plastic analysis of the image that includes three levels:

1. topological organization, where the constitutional elements of the image are identified;

2. eidetic organization, where the lines of the visual object analyzed are highlighted;

3. chromatic organization.

After having identified these three characteristics, we find the plastic formats that allow to reach the content, that is the transition from the signifier to the meaning, which are divided into two aspects:

1. the symbolic correlation, that is the set of conventions and cultural aspects connected to the expression plane (for example if the gold color indicates sacredness, the subject / object depicted that dresses gold, will be a sacred subject / object);

2. the semisymbolic correlation, which provides a relationship between a category of the expression and one of the content (for example the topology / topology category, can correspond to one of the content where "high" corresponds to "sacred" and "low" to " profane".

The application of this methodology aims to understand the presence or absence of regularity in the choice and, therefore, creation of a false identity. 

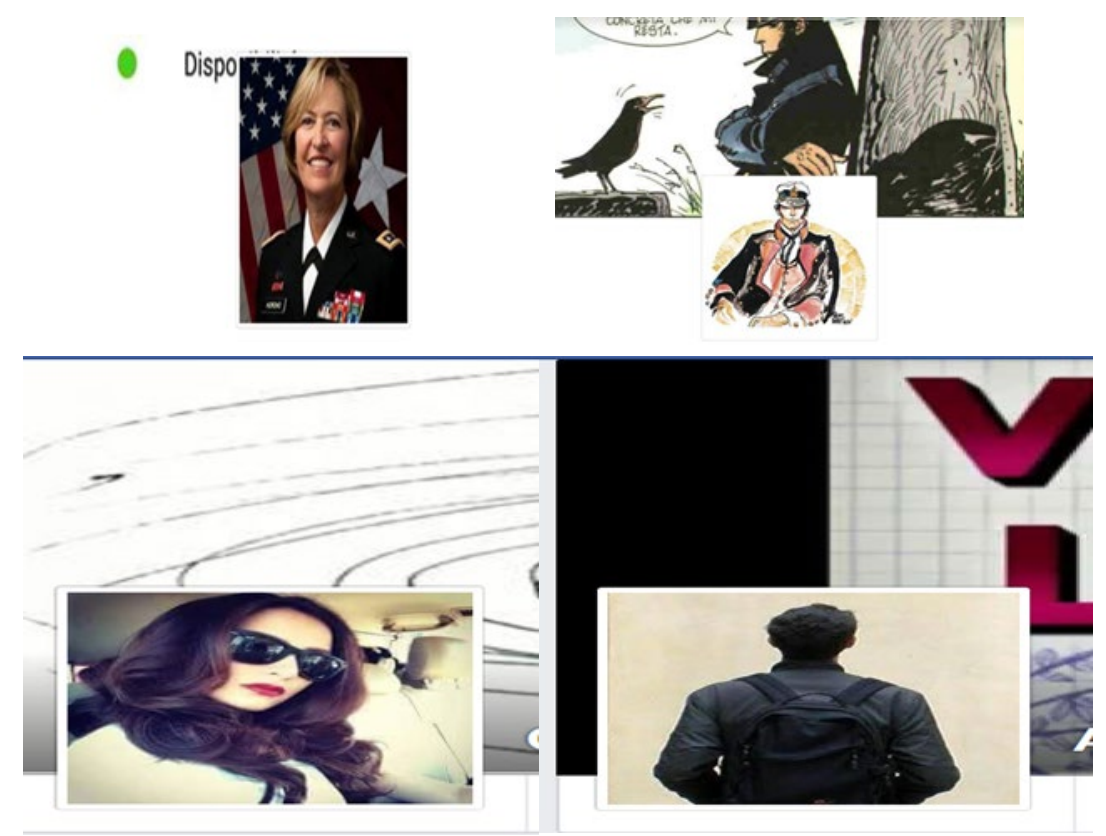

Figure 1. Examples of recognized false profiles

In the images shown as examples of recognized false profiles, it can be noted at the topographical level that the chosen subjects are always in the foreground, as if to indicate the desire to imitate real profiles. The subjects depicted are almost all in a central position, except in the case of Profile 3, whose character is slightly moved to the left. All subjects are in a frontal position, except for the one shown in Profile 4, which is shown with shoulders. All images have light colors, almost tending to blur, except in Profile 1.

An often common feature in the creation of false profiles is the choice to be represented by known figures, but which are not known to all social strata of the population. For example, Profile 1 chose the image of Patricia Horoho, a woman general of the US Army, known as "Heroine Nurse" (literally 'Nurse Hero'); similarly, in Profile 3 the Filipino actress and singer Jennylyn Mercado is portrayed. The false profile, therefore, interacts with people of different cultures, different ages from the character that represents it, in a background where it is difficult to recognize, but in which it can have all the characteristics of a real identity: for example photos in which the character shows his own face, but not totally, perhaps with his eyes covered, as the eyes are one of the distinctive traits of a human being. In addition, the choice of a female figure helps to be more attractive, since if the target of the interaction is a man, with an attractive woman as a profile image, you are more likely to succeed; if the target of the interaction, on the other hand, is a woman, the female image can be more reassuring and therefore favor the success of the interaction.

In other cases, on the other hand, the objective of the false profiles is precisely that of being identified, but the choice of an image with respect to another depends on which message one wishes to transmit. For example, in Profile 2, the choice fell on a typical representation of Corto Maltese, a character of comics, a lover of adventure and freedom. This shows that fake wants to act online in an undisturbed way, having the right to freedom. While in Profile 4 the figure shown is not recognizable and looking from the other side of the screen, it provides as an ideal to look beyond the screen.

Even the choice of the name of a false virtual identity is significant and not casual. The analysis of the above profiles shows that: in many cases the names and surnames are 
composed of the same number of letters as the real name and surname; in other conditions it is acronyms of the letters of the real name and surname; in others, the same name is used and as a surname a number, generally the number "one" to indicate a certain degree of supremacy compared to other fakes or to pretend the truthfulness of one's own identity (for example "Antonio Uno").

These profiles, in addition to being false, also have the function of defamation, provocation, but also to cheat other users. Another common indicator concerns the activity on profiles: these profiles share few contents, post a few photos, have very low online activities, but all interactions take place outside their profiles. The privileged terrain of attack of the trolls are the Facebook groups, virtual places where there are more Internet users who have a common objective of discussion. But what happens when other Internet users recognize the trolls? What do the real identities feel?

\section{Troll Hunt and Senti-ment}

In post-modernity, society experiences a great paradox: the diffusion of algorithms and the scientific nature with the constant claim of the search for truth on the part of alterity, which however continually clashes with modern liquidity, leaving the human being in fragility. A concrete example of this fragile and uncertain life is outlined in the discommunications between true and false profiles, which have the aim of provoking real identities. What happens when on the part of the real profiles the expectations of truth placed in the mediated communication act are not respected? On the contrary, what are the false profiles trying to 'control' when they are 'unmasked'? In order to answer these research questions, in order to understand if the methods of interaction can be predicted to implement the algorithms in the recognition of false provocative profiles, a quantitative-qualitative methodology has been used on 15 interactions between the four above-mentioned troll profiles and users. real on Facebook. The research was carried out looking for the name of the false profile and collecting the communication acts mediated in the "post" section: in this way, 62 comments from real users and 54 comments and posts of the false profiles were analyzed. Considering these extracts as diatests, whose practice of understanding the meaning depends on the dense network of text and context, an Emotional Analysis was carried out using the IBM "Tone Analyzer" software, which allows to obtain as output the prevailing basic emotion. In the case of the trolls' speeches, the prevailing emotion confirmed is the anger, as shown in Figure 2.

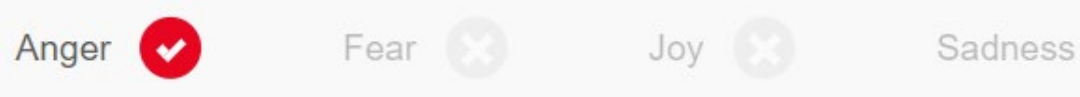

Figure 2. Emotional Analysis output of troll speech

At the micro-text level, the software allows to evaluate the individual aspects that allowed the calculation of the prevailing emotion. In the case of trolls, the function of anger as emotion is to evoke a sense of injustice: to create a false identity and to provoke a sense of injustice, as in the following example:

Eg. "Cresci e impara signorina o chi per te sta scrivendo trovare un posto di lavoro a tutti quelli a cui hai promesso ma prima per te perchè con il tuo alzamano è giusto che tu abbia un lavoro"

In this example, which the software deemed containing anger, highlights aspects related to injustice and humiliation. The false identity and the lack of recognition is a defense of the real identity, this allows us to say what we think without suffering social 
repercussions just because we can not identify them; on the contrary, instead, real users who need veiled rhetorical strategies, such as irony, in order not to understand the true meaning of the message.

But the provocation is not built only in the contents of the message, but also in the form. In fact, they are recognizable provocative linguistic structures, such as the use of a trivial lexicon. In this regard, due to the netiquette present in social networks and the fear of any possible censorship, any dirty words are partially obscured, as in the following example:

Eg. "E poi ci sono loro quelli che condividono qualsiasi cosa di un solo personaggio quelli che non hanno sfere per dire qualcosa di proprio quelli senza personalità quelli senza P...E.......inutile DIFFERENZIARLI"

In addition, the use of incorrect or minimal punctuation, as well as the use of grammatically incorrect verbal forms, is another attempt to make oneself unrecognizable. On the part of the real user this aspect is perceived as interfacing with an unacculturated identity. In reality, the degree of education is another element of recognition, so the task of a false profile with provocative intent is also to build the whole message, lying more on the form than on the content. For this reason, latency times in responses from a troll profile also increase. Indeed, to the following attack by a real user "You are a Fake and a false can not but come fake", the false identity with provocative intentions insists on the veracity of the affirmed contents, as in the following example: "I am a FAKE, but what I say is truth! ".

\section{CONCLUSION}

In a post-modern world governed by algorithms, where there is a claim to values such as honesty and truth, "liquid" identities emerge. These are identities created specifically to provoke real users in virtual places where they discuss topics that segment the population into two or more factions: these identities insinuate themselves in these fractures and have the aim of recalling a sense of justice without, however, "Put your face". In the study, four fake Facebook profiles were analyzed, which were unmasked by real users, in the interactions they admitted to be false profiles with provocative intent, then troll profiles.

On the basis of these results, it is expected that the identification of these significant characteristics may support the creation of algorithms able to favor the identification of a dataset useful for the promotion of a digital culture, aimed at eliminating the gap between the real individualities. and virtual, in the perspective of a "global village" (McLuhan, 1964), in which the Net is not evil, but the place where connective intelligence develops.

\section{REFERENCES}

Andreassen, C. S., Griffiths, M. D., \& Gjertsen, S. R. (2013). The relationships between behavioral addictions and the five-factor model of personality. Journal of Behavioral Addictions, 2, 90-99. https://doi.org/10.1556/JBA.2.2013.003

Bessière, K., Seay, A. F., \& Kiesler, S. (2007). The ideal elf: Identity exploration in World of Warcraft. CyberPsychology and Behavior, 10, 530-535. https://doi.org/10.1089/cpb.2007.9994

Buckels, E. E., \& Paulhus, D. L. (2013). Comprehensive assessment of sadistic tendencies $(C A S T)$. Unpublished measure, University of British Columbia. 
Online Journal of Communication and Media Technologies, 2019

Buckels, E. E., Jones, D. N., \& Paulhus, D. L. (2013). Behavioral confirmation of everyday sadism. Psychological Science, 24, 201-2209. https://doi.org/10.1177/0956797613490749

Buckels, E. E., Trapnell, P. D., \& Paulhus, D. L. (2014). Trolls just want to have fun. Personality and Individual Differences, 67(2014), 97-102. https://doi.org/10.1016/j.paid.2014.01.016

Coles, B. A., \& West, M. (2016). Trolling the trolls: Online forum users constructions of the nature and properties of trolling. Computers in Human Behavior, 60, 233-244. https://doi.org/10.1016/j.chb.2016.02.070

Coles, B. A., \& West, M. (2016). Weaving the internet together: Imagined communities in newspaper comment threads. Computers in Human Behavior, 60, 44-53. https://doi.org/10.1016/j.chb.2016.02.049

Cracker N., \& March E. (2016). The dark side of Facebook®: The Dark Tetrad, negative social potency, and trolling behaviours. Personality and Individual Differences, 102, 79-84. https://doi.org/10.1016/j.paid.2016.06.043

Ditrich, L., \& Sassenberg, K. (2017). Kicking out the trolls - Antecedents of social exclusion intentions in Facebook groups. Computers in Human Behavior, 75, 32-41. https://doi.org/10.1016/j.chb.2017.04.049

Dunn, R. A., \& Guadagno, R. E. (2012). My avatar and me - Gender and personality predictors of avatar-self discrepancy. Computers in Human Behavior, 28, 97-106. https://doi.org/10.1016/j.chb.2011.08.015

Gambetta D. (2018). Datacrazia. Politica, cultura algoritmica e conflitti al tempo dei big data. Roma: D Editore

Gemma C., \& Quatera I. (2017) "Il sè digitale sulla pagina web" Quaderni della Scrittura n. 28. Barletta: Cafagna Editore.

Graham, L. T., \& Gosling, S. D. (2013). Personality profiles associated with different motivations for playing World of Warcraft. Cyberpsychology, Behavior, and Social Networking, 16, 189-193. https://doi.org/10.1089/cyber.2012.0090

Greimas, A. J. (1991). Semiotica figurativa e semiotica plastica, trad. it. L. corrain e M. Valenti (a cura di), Leggere l'opera d'arte. Dal figurativo all'astratto, Bologna, esculapio.

Hardaker, C. (2010). Trolling in asynchronous computer-mediated communication: from user discussions to academic denitions. Journal of Politeness Research, 6, 215-242. https://doi.org/10.1515/jplr.2010.011

Herring, S., Job-Sluder, K., Scheckler, R., \& Barab, S. (2002). Searching for safety online: managing "trolling" in a feminist forum. The Information Society, 18, 371-384. https://doi.org/10.1080/01972240290108186

Hyde, L. (1997). Trickster makes this world: Mischief, myth, and art. Macmillan.

John, O. P., \& Srivastava, S. (1999). The Big-Five trait taxonomy: History, measurement, and theoretical perspectives. In O. P. John \& L. A. Pervin (Eds.), Handbook of personality: Theory and research (pp. 102-139). New York: Guilford Press.

Joiner, R., Gavin, J., \& Duffield, J. (2005). Gender, Internet identification, and Internet anxiety: Correlates of Internet use. CyberPsychology \& Behavior, 8, 371-378. https://doi.org/10.1089/cpb.2005.8.371

Joiner, R., Gavin, J., \& Duffield, J. (2005). Gender, Internet identification, and Internet anxiety: Correlates of Internet use. CyberPsychology \& Behavior, 8, 371-378. https://doi.org/10.1089/cpb.2005.8.371 
Jones, D. N., \& Paulhus, D. L. (2014). Introducing the Short Dark Triad (SD3): A brief measure of dark personality traits. Assessment, 21, 27-40. https://doi.org/10.1177/1073191113514105

Juvonen, J., \& Gross, E. F. (2008). Extending the school grounds? Bullying experiences in cyberspace. Journal of School Health, 78, 496-505. https://doi.org/10.1111/j.17461561.2008.00335.x

Juvonen, J., \& Gross, E. F. (2008). Extending the school grounds? Bullying experiences in cyberspace. Journal of School Health, 78, 496-505. https://doi.org/10.1111/j.17461561.2008.00335.x

Lenhardt, A. (2013). Teens, smartphones \& texting. Washington, DC: Pew Research Center's Internet \& American Life Project.

Lévy P., L’intelligence collective. Pour une anthropologie du cyberspace, Paris, La Découverte, 1994; Lévy P., Collective Intelligence: Mankind's Emerging World in Cyberspace, New York, Plenum Presse, 1997) e intelligenza connettiva (Kerckhove).

Ljepava, N., Orr, R. R., Locke, S., \& Ross, C. (2013). Personality and social characteristics of Facebook non-users and frequent users. Computers in Human Behavior, 29(4), 1602-1607. https://doi.org/10.1016/j.chb.2013.01.026

Manuti, A., \& Mininni, G. (2017). A rose is more than a rose ... the diatextual constitution of subjects and objects. De Gruyter Mouton, 37(2), 243-263. https://doi.org/10.1515/text-2017-0005

McCosker, A. (2014). Trolling as provocation: YouTube's agonistic publics. Convergence: The International Journal of Research into New Media Technologies. https://doi.org/10.1177/1354856513501413

McCreery, M. P., Krach, S. K., Schrader, P. G., \& Boone, R. (2012). Defining the virtual self: Personality, behavior, and the psychology of embodiment. Computers in Human Behavior, 28(3), 976-983. https://doi.org/10.1016/j.chb.2011.12.019

McLuhan, M. (1964). Understanding media. New York: McGraw-Hill.

Paulhus, D. L., \& Jones, D. N. (2014). Measuring dark personalities. In G. J. Boyle, D. H. Saklofske \& G. Matthews (Eds.), Measures of personality and social psychological constructs. San Diego, CA: Academic Press (in press). https://doi.org/10.1016/B978-012-386915-9.00020-6

Paulhus, D. L., \& Williams, K. M. (2002). The dark triad of personality: Narcissism, Machiavellianism, and psychopathy. Journal of Research in Personality, 36, 556-563. https://doi.org/10.1016/S0092-6566(02)00505-6

Rosen, L. D., Carrier, L. M., \& Cheever, N. A. (2013). Facebook and texting made me do it: Media-induced task-switching while studying. Computers in Human Behavior, 29, 948-958. https://doi.org/10.1016/j.chb.2012.12.001

Rosen, L. D., Whaling, K., Rab, S., Carrier, L. M., \& Cheever, N. A. (2013). Is Facebook creating "iDisorders?" The link between clinical symptoms of psychiatric disorders and technology use, attitudes and anxiety. Computers in Human Behavior, 29, 12431254. https://doi.org/10.1016/j.chb.2012.11.012

Ruiz, C., Domingo, D., Mico, J. L., Díaz-Noci, J., Masip, P., \& Meso, K. (2011). Publicsphere 2.0? The democratic qualities of citizen debates in online newspapers. The International Journal of Press/Politics. https://doi.org/10.1177/1940161211415849

Ruiz, et al. (2011). Public Sphere 2.0? The Democratic Qualities of Citizen Debates in Online Newspapers. The International Journal of Press/Politics, 16(4), 463 - 487. https://doi.org/10.1177/1940161211415849 
Shachaf, P., \& Hara, N. (2010). Beyond vandalism: wikipedia trolls. Journal of Information Science, 36, 357-370. https://doi.org/10.1177/0165551510365390

Thacker, S., \& Grifths, M. D. (2012). An exploratory study of trolling in online videogaming. International Journal of Cyber Behavior, Psychology and Learning (IJCBPL), 2, 17-33. https://doi.org/10.4018/ijcbpl.2012100102

Toffler A. (1980). The Third Wave. New York: Bantam Books.

Turckle, S. (2005). The Second Self: Computers and the Human Spirit. Cambridge, MA: MIT Press, 2005. https://doi.org/10.7551/mitpress/6115.001.0001

Virkar, S. (2014). Trolls just want to have fun: electronic aggression within the context of e-participation and other online political behaviour in the united kingdom. International Journal of E-Politics (IJEP), $\quad 5, \quad 21-51$. https://doi.org/10.4018/ijep.2014100102

Zweig, J. M., Dank, M., Yahner, J., \& Lachman, P. (2013). The rate of cyber dating abuse among teens and how it relates to other forms of teen dating violence. Journal of Youth and Adolescence, 42, 1063-1077. https://doi.org/10.1007/s10964-013-9922-8

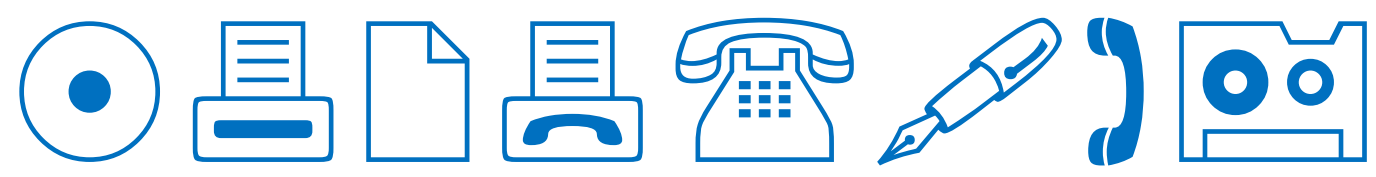

